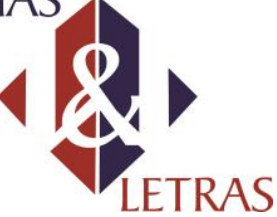

\title{
A Literatura Entre Fronteiras: Um Estudo Pela Perspectiva Semiótica De Greimas
}

\section{The literature between frontiers: a study for the semiotic perspective of Greimas}

\author{
Ricardo Santos David* \\ * Florida Christian University, FCU, Orlando - FL 32819, e-mail: \\ ricardosdavid@hotmail.com
}

\begin{abstract}
RESUMO: Partimos da ideia de que a semiótica greimasiana ajuda o leitor a entender o universo narrativo, neste artigo pretendemos fazer uma breve análise, visando a depreender o processo de valorização criativa, temática e figurativa na construção de narrativas literárias produzidas em zona fronteiriça por literatas de uma poética aqui nomenclaturada de literatura fronteiriça. Integram nesse estudo algumas propostas literárias que se desenvolvem tanto na fronteira brasileira, como na fronteira boliviana. A análise tem como base a semiótica francesa de Algirdas Julien Greimas. Focalizam-se, portanto as obras da fronteira, América Latina; Brasil-Bolívia, com um olhar sobre o ficcional fronteiriço como instrumento facilitador do entendimento desta literatura de fronteira e suas conexões significativas.
\end{abstract}

PALAVRAS-CHAVE: Semiótica francesa; Literatura de fronteira, Identidade; América Latina.

ABSTRACT: Starting from the idea that semiotics helps the reader understand the narrative universe. This article intends to make a brief analysis, aiming to conclude the process of valuing creative, thematic and figurative in the construction of literary narratives produced by literati in the border area of a poetic nomenclature of border literature here. Some proposals that integrate literary study that develop in both the Brazilian border, as the Bolivian border. The analysis is based on French semiotics of Algirdas Julien Greimas. They focus, then the works of the Latin American; Brazil-Bolivia border, with a fictional look at the border as an instrument facilitating the understanding of literature and its border meaningful connections.

KEY WORDS: Semiotics; Border literature; Identity; Latin America.

\section{INTRODUÇÃO}

Preliminarmente, vale destacar a importância do tema pesquisado. Faz-se necessário esclarecer que a integração política, econômica e cultural entre países latinoamericanos sempre despertou interesse, além de ser meta nas relações internacionais. Entretanto, ao que se refere ao estudo de interfluxos da produção literária fronteiriça, de modo geral, parece-nos ainda muito tímido. Comumente, assistimos a discussões em torno da literatura, de forma generalizada, mas ao que se refere à 




e-ISSN: 1981-4755

DOI: $10.5935 / 1981-4755.20170013$

literatura fronteiriça, pouco se tem abordado, considerando que, nos estudos contemporâneos, as relações entre o saber literário e os outros saberes são particularmente complexas e vão requerer do crítico certos entendimentos geopolíticos que permitam estabelecer aberturas interpretativas para, o que, aqui, de antemão, definiremos como uma "primeira aproximação".

Esta "primeira aproximação" com o texto fronteiriço, geralmente, não costuma ser tarefa simples, pois requer, inicialmente, um conhecimento considerável sobre a região. Em segundo lugar, um aprofundamento no discurso histórico, considerando que a memória da humanidade, a origem e evolução da sociedade, seu auge e decadência, os feitos e a trajetória de personagens ilustres, os antecedentes, e até situações contemporâneas do homem são temas históricos, parte fundamental da cultura individual e coletiva, que são conservados nos arquivos da história desta fronteira. Entende-se, ainda, que, em cada período literário, são atribuídas à literatura de fronteira funções distintas, condizentes com a realidade cultural e, portanto, social, da época. Assim, a linguagem literária fronteiriça assume aspectos de representação e demonstração identitárias, ou seja, reflete uma identidade nacional, evolui proporcionalmente, ganha diversas "roupagens". Nessa perspectiva, vê-se, então, que o sistema literário fronteiriço se organiza em torno da problemática da identidade nacional, fortalecida na ideia de "pertencimento" a uma nação. Essa função é que possibilita ao indivíduo o reconhecimento da realidade que o norteia.

Em terceiro lugar, sabe-se que a literatura fronteiriça, assim como a literatura de forma geral, está ligada à demonstração do real, assumindo funções enquanto fruidora da arte narrativa. Antonio Candido, em A literatura e a formação do homem (CANDIDO, 1972) identifica três funções exercidas pela literatura, as quais são denominadas de humanizadoras: a psicológica, a formadora e a social. Esta primeira função tem ligação estrita com a capacidade e necessidade que o individuo tem de fantasiar através dos devaneios. Conforme Candido, as fantasias expressas pela literatura, no entanto, têm sempre sua base na realidade, nunca são puras e, é justamente através dessa ligação com o real, que a literatura passa a exercer sua segunda função: a formadora. Entretanto, para Candido, "a literatura pode formar; mas não segundo a pedagogia oficial”, " ela age com o impacto indiscriminado da própria vida e educa como ela" (op. cit., p. 805). Assim, a literatura atua como instrumento de formação do homem, exprimindo realidades que a ideologia dominante tenta, por vezes, esconder. Para Candido, a literatura não corrompe nem edifica, mas humaniza em sentido 


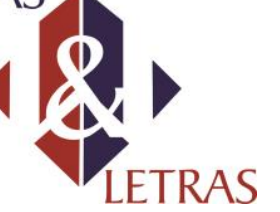

e-ISSN: 1981-4755

DOI: $10.5935 / 1981-4755.20170013$

profundo, por que faz viver (op. cit., p. 806). Desta forma, identifica-se a terceira função da literatura que diz respeito à identificação do leitor e de seu universo vivencial representados na obra literária: a função social.

Essa última função possibilita ao indivíduo, segundo Candido, o reconhecimento da realidade que o cerca quando transposta para o mundo ficcional. Contudo, pode, por vezes, causar uma falsa impressão, construindo um reconhecimento errôneo, na visão do leitor, quando este não reconhece a realidade e não participa diretamente dela. Dessa maneira, o leitor que não participa da realidade fronteiriça, nem reconhece a história em que a personagem está inserida, e atua, apenas, como observador, reconhece somente a realidade de seu próprio mundo como verdade absoluta, não interpretando adequadamente o produto ficcional. Desta forma, essa função pode causar a integração do leitor ao universo vivencial das personagens fronteiriças retratadas, quando expressa de maneira fidedigna sua realidade vivencial. Isso causa uma maior integração entre leitor e personagem, que culmina na identificação de uma realidade que não é a de quem lê, e, por sua vez, que faz parte de uma cultura fronteiriça própria, diferente daquela da qual, muitas vezes, o leitor participa. Essa integração faz com que o leitor integre a realidade da obra de fronteira às suas próprias experiências pessoais.

Sobre a ideologia dominante, denominada de rede de poder, pode-se destacar que para (Foucault, 1993), não existe no singular, mas muitos poderes ou formas de dominação, que são sempre locais e regionais. Possuem sua própria modalidade de funcionamento e são todas formas heterogêneas de poder. Isto é, o poder não se exerce territorialmente só de cima para baixo, dos altos escalões territoriais para baixo, mas a estrutura do poder baseia-se também no poder que emana dos escalões inferiores. Consequentemente, poderíamos afirmar que, na visão desse autor, o poder, na literatura fronteiriça, poderia ser também heterogêneo. Ratifica Lavoura (2009) que o poder circula, não é localizado em lado algum, exerce-se plenamente em rede.

Coincide destacar que "O poder visa o controle e a dominação sobre os homens e sobre as coisas. O território não é menos indispensável, uma vez que é a cena do poder e o lugar de todas as relações. O território é um trunfo particular, recurso e entreve, continente e conteúdo, tudo ao mesmo tempo". (RAFFESTIN, 1993, p.58). É, por isso, o poder exercido por pessoas ou grupos, que define um território. Percebe-se que para Claude Raffestin, território e poder estão simetricamente relacionados. Assim, o sentimento nacionalista de fronteira deve ser analisado paralelamente ao processo de territorialização proposto por Raffestin que não se restringe apenas à apropriação física, 


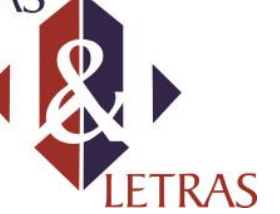

material, mas também imaterial ou simbólica: "a imagem ou modelo, ou melhor, toda construção da realidade, a representação sobre o território, é um instrumento de poder e isso desde as origens do homem" (RAFFESTIN, 1993. p. 145).

De qualquer modo, abordar literatura de fronteira, em especial a literatura desta fronteira Brasil-Bolívia, é expressar-se em estudos identitários, frutos de fluxos constantes que as atravessam, para desvendar as personagens, muitas vezes, derivadas de conflitos de classe, e de tensões étnicas; presentes no território latino. Certo é que as fronteiras e os limites entre o saber contido na literatura de fronteira, em suas relações com as teorias disponíveis e aquelas a serem ainda pensadas, não deixam de ser circunscritos pela velha relação entre as correntes textualistas e as influências contextuais percebidas no âmbito de uma obra literária. Ainda assim, no caso da produção ficcional produzida nesta zona fronteiriça, convém destacar alguns aspectos relevantes, que lhes são peculiares.

Desse jeito, em um primeiro momento, percebe-se que os estudos que relacionam a literatura fronteiriça Brasil-Bolívia devem ser norteados por duas concepções: a da história cultural e da história social de cada região. Agora, vale, aqui, salientar que não se trata de analisar as obras com visão totalmente histórica, afinal, o discurso histórico produz interpretações das informações ou conhecimento do passado que dão tratamento narrativo ao fato para que se percebam seus referentes como fenômenos distintivamente "históricos". Finalmente, de acordo Croce apud Sutermeister (2009), onde não há narrativa, não existe discurso distintivamente histórico. Não obstante, deve-se recorrer à história com o intuito de compreender a realidade em que os autores fronteiriços estão incluídos e, posteriormente, analisar com base nas teorias da literatura.

\section{LITERATURA, IDENTIDADE NACIONAL E PATROTISMO}

\section{A FRONTEIRA BRASILEIRA}

Pensar a formação da identidade nacional na literatura fronteiriça com os mesmos critérios que explicam a formação da literatura nacional ajuda a explicar o sentimento de "missão" que marca desde os primeiros autores até os mais modernos (SILVA, 2007, p. 121), visto que, o nacionalismo crítico, desde o início da literatura brasileira, constituiu fator de eficácia estética e, para crítica, foi recurso ideológico 


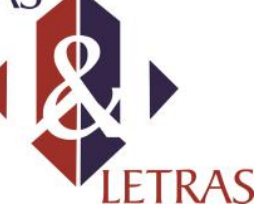

e-ISSN: 1981-4755

DOI: $10.5935 / 1981-4755.20170013$

compreensível em uma "fase de construção e autodefinição" (CANDIDO, 1981). Procura-se, logo, uma análise literária fronteiriça, desde uma reflexão na questão do nativismo, sentimento de amor pelo país, do patriotismo, o amor pela nação, a partir dos habilidosos artistas do verso memorialista, de um passado histórico, dos nacionalistas regionalistas, da exaltação da natureza pátria, até os neo-nacionalistas, em suas múltiplas facetas, repletos de coloquialidades desarticuladas, sem arcaísmos, sem erudições, que refletem esse espírito nacional de fronteira.

Desta forma, a literatura da fronteira brasileira apresenta-se, pelo nativismo, o sentimento de amor pelo país, feito pela exaltação da natureza pátria, como em Pedro de Medeiros, 1967) "E Corumbá surgiu, por sobre a terra branca... entre o verde dos montes, no alto da barranca..." , e como em D. Aquino Corrêa (1917) “Corumbá... a deusa Vênus... flor do lindo Pantanal bravio, tão bela és tu que o teu selvagem rio... dá longas voltas, por que, ao menos, possa contemplar teu mimoso casario...", associado ao próprio patriotismo, amor pela nação, por meio dos artistas memorialistas, dos regionalistas, como em Carlos Vandoni de Barros (1934) "Um pedaço de chão agreste e altivo, neste extremo da Pátria soberana, assim és, Corumbá, qual marco vivo, consciente da missão, honrosa e ufana!”, como em José de Mesquita (1919). “Dois anos de tristeza e de opróbrio curtira a infeliz Corumbá, em poder do estrangeiro", como em Renato Báez, este que, distante de poeta e ensaísta, destacou-se como grande historiador, com inúmeras obras publicadas, inclusive de outros autores da região, até os supracitados, ou como em Otávio Gonçalves Gomes, poeta panteísta, divulgador dos guaicurus, e sua obra "Onde Cantam as Seriemas", até os neo-nacionalistas, que, paradoxalmente, ofuscam e refletem profundas crises sociais, financeiras e econômicas e, repletos de coloquialidades desarticuladas, sem arcaísmos, sem erudições, como Ulisses Serra em “ Camalotes e Guavirais", Lobivar Matos em "Sarobá" e “Areôtorare”, e em Manoel de Barros, um dos principais poetas contemporâneos da fronteira brasileira sul-mato-grossense, que juntos refletem a montanha de preconceitos arcaicosos no âmbito desse espírito nacional de fronteira.

Nesta ocasião uma poesia tipicamente modernista, com linguagem simples e de fácil compreensão, sem métricas, sem rimas, sem exaltações, ora pela própria descontrução da linguagem, do niilismo, e da descontextualização, características da poesia pós-moderna e que significam revolução, corte, ruptura, reflexo de um mundo em caos, ou seja, a redução de tudo a nada, numa descrença absoluta, a literatura desta fronteira segue tecendo marcas peculiares que refletem sua identidade nacional 


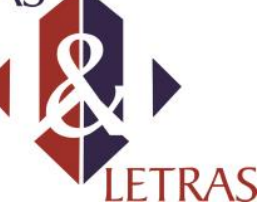

fronteiriça. Desse jeito, por meio do estudo desse território, lugar de todas as relações, e, é claro, das territorialidades, surge à compreensão do sentimento nacionalista de fronteira que, por sua vez, é gênese da essência literária nacional fronteiriça, incorporada ao localismo, economia, política, etnia e cultura.

Condiz destacar que este artigo se propõe a um estudo referente à conformação de identidades fronteiriças, frutos de multiculturalismo e transnacionalização, alimentada dos fluxos migratórios constantes que atravessam essa fronteira e seus reflexos na literatura. A zona fronteiriça se caracteriza por uma mescla de culturas e de identidades. "La frontera es una gramática abierta, um texto inconcluso que se elabora desde múltiples miradas y acepta muchas lecturas”. (Arce, 2000). É uma porta de vaie-vem, e como tal nunca está escancarada, nem nunca está fechada (SANTOS, 1994).

Assim, é necessário ler as narrativas poéticas da literatura de fronteira conferindo a devida atenção à oposição entre seu plano de conteúdo, que está relacionado aos valores histórico-social devidamente figurativizado e tematizado, e seu plano de expressão, que se relaciona à realização estética, atentando à utilização estratégica dos recursos que irão produzir os efeitos de sentido desejado pelos autores fronteiriços.

\section{LITERATURA, PANORAMA HISTÓRICO, UM BREVE RELATO DA AMÉRICA LATINA}

\section{A FRONTEIRA BOLIVIANA CONTEXTUALIZADA}

Em relação à literatura da fronteira boliviana, não se deve delimitar ao departamento de Santa Cruz, apenas pelas cidades de Puerto Suarez e Puerto Quijarro, pois, apesar de serem ricas em cultura, pouco se pode encontrar em literatura escrita. As tradições são preservadas, em parte, pela tradição oral. Aqui se confirma à dificuldade histórica em adentrar nos estudos literários da região. Não obstante, sabe-se que ela originou-se, verdadeiramente, pela “Guerra del Chaco” (1932-1935), e pela Revolução de 1952 que destacaram aspectos particulares no indigenismo local. Assim, teve seu maior desenvolvimento no último século, conforme afirma Gabriel René Moreno, importante crítico literário boliviano, que registra ser "a partir la Guerra que se produce um movimento cultural generalizado".

(...) la producción literaria de Bolívia es muy reciente, si consideramos que es a partir de la Guerra del Chaco que se produce um movimento cultural generalizado, que se traduce por uma obra no solamente

Volume 18

Número 40 


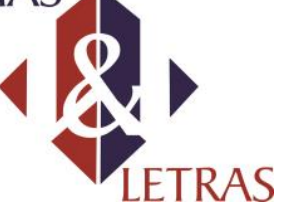

abundante, sino mejor inserta em la problematica social y política del país. (MORENO, 1864, p. 177)

Entretanto, até o fim do século XIX, a literatura boliviana se reduzia a alguns ensaios escritos, em sua maioria, escritos "por los hombres de estado”. Além disso, na Bolívia, o acesso à educação escolar sempre foi privilégio dos "blancos”, ou quando muito, dos "cholos", ficando a maior parte da população, os índios, excluídos do sistema escolar. Prontamente, não se poderia esperar que a literatura tivesse grandes manifestações fora dos círculos do poder. Assim, entre as obras de autores bolivianos, entretanto, destacamos "Juan de la Rosa. Memoria del último soldado de la independencia” de Nataniel Aguirre, grande escritor de novelas históricas, que tem por tema "las guerras de la Independencia”, e apresenta-se, então, como um relato testemunhal. Seguidamente, salientaremos "Raza de Bronce", um "alegato" realista, sem lugar para idealizações e eufemismos, em favor do índio explorado e reprimido pelos latifundiários, no qual apresentam vocábulos de origem aimará, posteriormente explicitados na própria obra, e "Pueblo Enfermo" obra que atribui ao mestiço à culpa de todos os males do país, ambas de Alcides Arguedas. Salienta-se que os ideais bolivarianos de unidade continental aparecem reafirmados como devaneios oníricos, pois esse ódio ao mestiço, "usurpador de los privilegios", também é encontrado em outros autores indigenistas bolivianos, admiradores de "la pureza de la raza".

Percebe-se que essas obras refletem o desejo dos autores bolivianos de conduzir os leitores a um plano extraliterário, camuflando a recriação e a interpretação muito particular desse universo desigual. A denúncia da exploração dos índios, no campo literário fronteiriço da Bolívia, expõe uma fermentação social profunda ao mesmo tempo em que ajuda a repensar movimentos e lutas sociais, ou seja, os problemas humanos dos grupos desprotegidos.

Desta maneira, a linguagem usada nas obras é um elemento importante na tentativa de apreensão da realidade. Em grande parte das narrativas, utiliza-se a linguagem que mais se aproxima da falada pelas camadas médias e populares e que se afasta do formal, em busca daquela que representa com fidelidade a índole mais profunda.

\section{O PANORAMA DA SEMIÓTICA DA LITERATURA DE FRONTEIRA}

\section{BRASIL E AMÉRICA LATINA: FATOS POLÍTICOS, HISTÓRICOS E CULTURAIS}

Sabe-se que as imagens e os símbolos, ao longo da história, têm exercido um papel fundamental na vida do homem, haja vista que lhe possibilita expressar-se de Volume 18

Número 40 


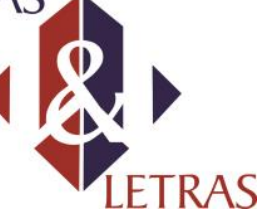

e-ISSN: 1981-4755

DOI: 10.5935/1981-4755.20170013

forma racional ou através do inconsciente. "O símbolo revela certos aspectos da realidade - os mais profundos que ficou na memória que desafia qualquer outro meio de conhecimento" (ELIADE, 1996). Em relação às obras fronteiriças Brasil - Bolívia, não é diferente, estas também são carregadas de símbolos e imagens a fim de reconstituir a história de região. Além de enriquecer, estilisticamente, a narrativa de fronteira, com uso de tais elementos simbólicos, a obra reflete a notabilidade de criação artística inovadora. Assim, a criação artística fronteiriça, evidenciada tanto na forma de articular as palavras, renovando a linguagem, lançando neologismos, incluindo outras línguas, inclusive indígenas, em seus textos, como na maneira de ultrapassar o mundo utilitário, e adentrar ao mundo do "maravilhoso" e da magia, revela as identidades nacionais, ao mesmo tempo em que rememora entidades e fatos políticos, históricos e culturais.

Sabe-se que em Greimas (1973), o signo não é definido como tal, ou seja, ele não apresenta nenhuma terminologia que possa representar o conjunto das significações, como fizeram Saussure, Peirce, Borba ou Mikhail Bakhtin. Mas, apesar de não apresentar um "rótulo" para designar o significante e o significado, criados por Saussure e aperfeiçoados pelos semioticistas ulteriores a ele, Greimas coloca duas terminologias, dentro de um conjunto abstrato, quando pressupõe a inexistência de um sem o outro. Portanto, se o significado não é possível sem o significante, eles se "inter-relacionam", completam-se. Percebe-se em Greimas uma manifestação figurativa e uma não figurativa, esboçando a diferenciação entre tematização e figurativização. A diferença entre as duas, para ele, reside no fato de que o não figurativo é considerado abstrato e definido por sua baixa densidade sêmica, enquanto o figurativo é concreto e definido por uma densidade sêmica maior. Aponta-se, então, para o fato de que concreto poderia ser o semema cujos "semas a partir dos quais a denominação se constrói dependem do mundo das qualidades sensíveis". Para Greimas, há duas classes de textos: os figurativos e os não figurativos. Exemplifica-se esse fato dizendo que a poesia forma a forma figurativa, enquanto as teorias estéticas manifestam-se de maneira não figurativa.

Após esses esclarecimentos, pode-se compreender que analisar as ficções fronteiriças é, antes de qualquer coisa, desvendar o figurativo. Mas, as teorias de Bakhtin é que nos possibilitam reconstituir concepções literárias a partir de uma visão totalizante da realidade, compreendendo o sujeito como um conjunto de relações sóciohistóricas, considerando que, nessas regiões fronteiriças, a linguagem literária possui infinitas possibilidades, o que na reflexão bakhtiniana, refletem os diferentes discursos 


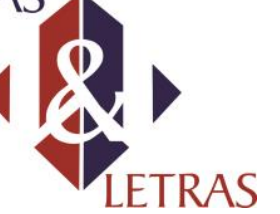

e-ISSN: 1981-4755

DOI: $10.5935 / 1981-4755.20170013$

que configuram uma comunidade, uma cultura, e uma sociedade. Para Bakhtin, a consciência, então, é engendrada pelas relações que os homens estabelecem entre si no meio social através da mediação da linguagem (Blanck, 1996). Bakhtin, ainda, desenha uma sociologia do discurso, chamando a atenção para o fato de que o discurso verbal, em qualquer esfera da vida, não pode ser compreendido fora da situação social que o engendra, não existindo isoladamente na medida em que participa do fluxo social em um constante processo de interação e troca com outras formas de comunicação (Brandão, 1997).

É inegável que, os caminhos da análise das práticas de linguagem fronteiriça refletem, num ir e vir entre discursos artísticos e cotidianos, a história, a cultura, a vida e o conhecimento compartilhado dos participantes, e dos contextos sociais nos quais estão inseridos, suas construções identitárias situadas sócio-historicamente no universo da fronteira. Desta maneira, os literatas nacionalistas brasileiros realçam o tamanho e a beleza do território, o desenvolvimento econômico do país comparado com os outros países vizinhos, e o privilégio desse fato. Todavia, passam a fazer "germinar", nas obras, estrangeiros decadentes, bêbados, prostitutas, maltrapilhos e loucos, como o lunático Mário-pega-sapo, "habitante de uma draga abandonada à beira do rio", presença constante nas obras manoelinas. Também presentificam as obras de autores fronteiriços, as Lavadeiras, mulheres conformadas, que apanham dos maridos, dos vagabundos, que bebem cachaça nos boliches e, espancam seus filhos, ou ainda, o Pequeno Engraxate risonho das mãozinhas pretas por trabalhar bastante pra ganhar dinheiro, personagens lobivarianas, ambos grandes autores da fronteira brasileira. Desta maneira, mergulhar nesse estudo semiótico é poder desvendar os "pobres-diabos", personagens como Bola Sete, Maria-pelego-preto etc. "Todos bêbados ou bocós", nos quais os autores expressam toda sua identidade nacional.

\section{CONSIDERAÇÕES FINAIS}

Em vista disso, é importante dizer que é na história da existência humana, repleta de símbolos, que o autor fronteiriço expressa suas imagens, que, muitas vezes, substituem as palavras ou dão-lhe outros sentidos, falam mais alto, representam muito mais do que a personagem e representam sua própria identidade por meio da palavra. Deve, o leitor, então, analisar as imagens, os símbolos e suas representações através dos personagens, revelando suas identidades fronteiriças, relacionando-os aos fatos 


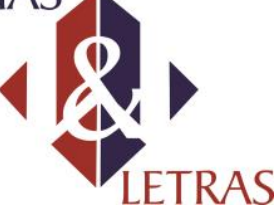

ocorridos na história da região. Mesmo assim, salientamos, aqui, que essas reflexões iniciais, ainda que embrionárias, e visam a retratar paradoxos e encontros característicos da evolução semiótica da literária nesta fronteira, tendo como base o estudo de signos específicos, América Latina em questão. Considera que as fronteiras entre países são espaços de trocas e de fragmentações culturais e a orientação axiológica do escritor determina o seu corpus literário. A semiótica do grego semeiotiké, arte dos sinais: ciência dos signos e da semiose, quer dizer, do processo de significação na natureza e na cultura, aqui, nos ajuda ao estudo das representações das coisas e seres do mundo presentes na mente do autor de fronteira, auxiliando-nos a, assim, a interpretar as personagens, as mensagens e os objetos. Ainda assim, compreender o alcance literário fronteiriço é ir mais além, e perceber os enredos literários da diferença e na diferença fronteiriça, o que, certamente, podem ser uma das chaves para se desvendar o universo literário da fronteira Brasil-Bolívia, ou seja, a gênese literária nacionalista de ambas.

\section{REFERÊNCIAS}

ARCE, José Manuel Valenzuela (2000). Al otro lado de la línea. Representaciones socioculturales en las narrativas sobre la frontera México-Estados Unidos. Revista Mexicana de Sociología, México DF, vol. 62, n. 2, Abril-Junio, pp. 125-149

BÁEZ, Renato. Corumbá: figuras e fatos. Bauru: 1964.

BAKHTIN, Mikhail. Estética da criação verbal. Tradução Paulo Bezerra. São Paulo: Martins Fontes. 2003.

BARROS, Manoel de. Gramática expositiva do chão. Rio: Civil. Brasileira, 1990. Livro sobre nada. Rio de Janeiro: Record, 2000. . Memórias Inventadas: a infância. S.Paulo, Planeta, 2003. XVI poemas.

BLANCK, Guillermo. Vygotsky: o homem e sua causa. In: MOLL, L. C. (org) Vygotsky e a educação: implicações pedagógicas da psicologia sócio-histórica. Porto Alegre: Artes Médicas, 1996.

BRANDÃO, Helena H. Nagamine Escrita, Leitura, dialogicidade. In: BRAIT, Beth (Org.). Bakhtin, dialogismo e construção de sentido. Campinas: UNICAMP, 1997.

CANDIDO, Antonio. A literatura e a formação do homem. Ciência e Cultura, São. Paulo, v. 24, n. 9, p. 803-809, 1972.

Formação da Literatura Brasileira: Momentos Decisivos. 6 ed. Belo

Horizonte: Editora Itatiaia, 1981.

ELIADE, Mircea. Imagens e símbolos: Ensaio sobre o Simbolismo mágico-religioso. São Paulo: Fontes, 1996.

FOUCAULT, Michel, Microfísica do Poder (1979), trad. de Roberto Machado, São Paulo, Edições Graal, 2007.

LAVOURA, Luis Manuel da Silva. Poder e Subjetivação Segundo Foucault e Deleuze. Dissertação de Mestrado em Filosofia Moderna e Contemporânea. Faculdade de Letras. Universidade do Porto. Abril, 2009.

MATOS, Lobivar. Areôtorare Poemas Boróros. Rio de Janeiro: Irmãos Pongetti, 1935. Sarobá; poemas. Rio de Janeiro: Minha Livraria Editora, 1936. 


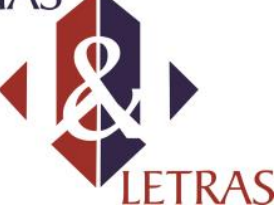

MORENO, Gabriel René. Introducción al Estudio de los Poetas Bolivianos. Santa Cruz de la Sierra: 1864.

RAFFESTIN, Claude. Por uma geografia do poder. São Paulo: Ática, 1993.

SANTOS, Boaventura de Souza. Modernidade, identidade e a cultura de fronteira. Tempo Social; Revista de Sociologia da USP, S. Paulo, 5 (1-2): 31-52, 1994.

SERRA, Ulisses. Camalotes e guavirais. 2. ed. Campo Grande: Tribunal de Justiça de Mato Grosso do Sul, 1989.

SILVA, Rosana Rodrigues da. A Poesia Mato-grossense na Mira do Historiador, Crítico e Poeta Rubens de Mendonça. In Terra roxa e outras terras - Revista de Estudos Literários. Volume 9. 2007. ISSN 1678-2054.

SUTERMEISTER, Paul. A meta-história de Hayden White: uma crítica construtiva à "ciência" histórica. Universidade Estadual de Maringá-UEM. Revista Espaço $\begin{array}{llllll}\text { Acadêmico, } & \mathrm{n}^{\circ} & 97, & \text { junho } & \text { de } & 2009\end{array}$ http://periodicos.uem.br/ojs/index.php/EspacoAcademico/index. Acessado em 17 de Setembro de 2010. 